\title{
Participação da Terapia Ocupacional na equipe do Programa de Seguimento de Prematuros Egressos de UTINs ${ }^{1}$
}

\author{
Dani Laura Peruzzolo ${ }^{a}$, Katine Marchezan Estivalet ${ }^{a}$, Andressa Ribas Mildner ${ }^{a}$, \\ Mayara Caramês da Silveira ${ }^{a}$
}

${ }^{a}$ Curso de Terapia Ocupacional, Universitário de Santa Maria - UFSM, Santa Maria, RS, Brasil

\begin{abstract}
Resumo: O curso de Terapia Ocupacional da Universidade Federal de Santa Maria (UFSM) foi criado em 2009 e, desde então, seu corpo docente vem buscando a inserção em serviços de atenção à saúde. A UFSM tem dentro de sua estrutura o Hospital Universitário (HUSM), que oferece serviços das mais variadas complexidades. Dentre eles está o Ambulatório de Pediatria, que possui o Programa de Seguimento de Prematuros Egressos de Unidades de Tratamento Intensivo Neonatal (UTINs). Esse serviço foi criado, em nível governamental, e implantado em hospitais que são considerados referência regional para acompanhar bebês prematuros que recebem alta das UTINs. O aumento considerável de bebês que sobrevivem à prematuridade desencadeou a necessidade de um contínuo acompanhamento, pois mesmo com a alta hospitalar eles seguem sendo considerados de risco. Este artigo tem por objetivo apresentar um relato descritivo da experiência de participação do terapeuta ocupacional junto à equipe e à população atendida no Programa de Seguimento de Prematuros Egressos de UTINs do Hospital Universitário de Santa Maria. O relato é contextualizado pela descrição da proposta do programa de seguimento implantado no HUSM, apresentando os protocolos definidos pela equipe para avaliação, que foram: Bayley Scale of Infant Development, Teste de Triagem de Desenvolvimento de Denver II e Indicadores Clínicos de Risco para o Desenvolvimento Infantil. Em seguida apresenta-se o processo de inserção do terapeuta ocupacional no programa de seguimento e, finalmente, são destacadas algumas considerações sobre a contribuição do terapeuta ocupacional junto à equipe e à população atendida.
\end{abstract}

Palavras-chave: Nascimento Prematuro, Desenvolvimento Infantil, Terapia Ocupacional.

\section{The participation of Occupational Therapy in a team from the monitoring Program of Premature Infants Discharged from NICUs}

\begin{abstract}
The Occupational Therapy course of the Federal University of Santa Maria (UFSM) was created in 2009. Since then, its faculty has sought the inclusion in the three lines (primary, secondary and tertiary) of health care services. Within the university premises, there is a University Hospital (HUSM) that offers services in several complexities. The Pediatric Clinic, which holds the Monitoring Program of Premature Infants discharged from Neonatal Intensive Care Units (NICU), is among them. This service was created at government level and implemented in hospitals that are considered regional references to monitor premature infants discharged from NICUs. The significant increase in the number of infants who survive prematurity initiated the need for continuous monitoring, because infants are still considered at risk even after hospital discharge. This paper aims to present a descriptive report of the experience participation of the occupational therapist together with the team and the population that is attended in the Monitoring Program of Premature Infants discharged from the NICU of the HUSM. The report is contextualized by the proposal description of the Monitoring Program implanted at the HUSM, presenting the protocols defined by the assessment team, as follows: Bayley Scale of Infant Development, Denver Developmental
\end{abstract}

Autor para correspondência: Dani Laura Peruzzolo, Av. Roraima, 1000, Camobi, CEP 97105-900, Santa Maria, RS, Brasil, e-mail: danilaura@ig.com.br

Recebido em 7/8/2012; $1^{a}$ Revisão em 20/11/2012; $2^{a}$ Revisão em 4/3/2013; $3^{\text {a }}$ Revisão em 16/4/2013; $4^{a}$ Revisão em 3/6/2013; Aceito em 24/6/2013. 
Screening Test II, and Clinical Indicators of Risk for Child Development. After that, it presents the process of inclusion of the occupational therapist in the Monitoring. Finally, some considerations are highlighted in relation to the contribution of the occupational therapist to the team and the population attended.

Keywords: Premature Birth, Child Development, Occupational Therapy.

\section{Introdução}

O Curso de Terapia Ocupacional da Universidade Federal de Santa Maria (UFSM) foi criado em 2009, com ingresso da primeira turma a partir do segundo semestre. Desde então, seu corpo docente vem buscando a inserção em serviços de atenção à saúde nas três linhas (primária, secundária e terciária).

A UFSM tem dentro de sua estrutura o Hospital Universitário, que atende a população do município e de outras cidades da regiâo central do estado, oferecendo serviços das mais variadas complexidades, dentre os quais o Ambulatório de Pediatria, que mantém o Programa de Seguimento de Prematuros Egressos de Unidades de Tratamento Intensivo Neonatal (UTINs). Esse serviço faz parte de uma das propostas governamentais para a diminuição da mortalidade infantil, considerando que o Brasil assinou, em março de 2004, o Pacto Nacional para a Redução da Mortalidade Materna e Neonatal, assumindo o compromisso de executar açóes para a diminuição da mortalidade dessa população e fomentando a criação de serviços que qualifiquem $o$ atendimento a mães e seus bebês.

Outro conjunto de açôes constitui a assistência pré-natal. Segundo Diniz (2009), a Pesquisa Nacional de Demografia e Saúde 2 (2006) afirma que o acesso à consulta pré-natal já pode ser considerado universal, pois, nos cinco anos anteriores às duas pesquisas (1996 e 2006), o percentual de mulheres que não realizou nenhuma consulta durante sua última gravidez caiu de $14 \%$ para $1 \%$, incluindo-se a área rural. Em artigo intitulado Gênero, saúde materna e o paradoxo perinatal, Diniz (2009) lança algumas questóes importantes quanto à avaliação dos serviços nessa área. Entre elas, a informaçáo de que, apesar de os números indicarem a maior sobrevida dos bebês, o nascimento de prematuros aumentou.

Em Pelotas, os resultados de três coortes (1982, 1993 e 2004) mostram que a proporção de nascimentos prematuros aumentou de maneira marcante, de 6,3\% em 1982 para 14,7\% em 2004. Para os autores, náo foi possível explicar esse aumento através de mudanças nas características maternas, já que as mães em 2004 tinham melhores indicadores de saúde que as das coortes anteriores (DINIZ, 2009, p. 317).
$\mathrm{O}$ aumento de bebês prematuros direcionou algumas das políticas para esse programa de seguimento, buscando-se qualificação, tanto em equipamentos quanto em treinamento de pessoal. Os estados da federação foram estimulados a estudarem suas necessidades e elaborarem programas de incentivo, tais como: a Rede Cegonha ${ }^{3}$, a Rede Amamenta Brasil ${ }^{4}$ e a implantação do Método Canguru $^{5}$, entre outros programas.

Algumas dessas açôes interferiram diretamente na melhoria do atendimento das UTINs. Por meio de qualificação dos equipamentos (DINIZ, 2009) e com a implantação da "humanização da assistência" hospitalar já existem indicadores que apontam uma maior sobrevida dos recém-nascidos com menor idade gestacional e baixo peso (CARDOSO et al., 2010; MARTINEZ et al., 2007; SOUZA, 2010).

Criou-se então a necessidade de um acompanhamento diferenciado para essas crianças porque, mesmo após a alta hospitalar, elas continuam sendo consideradas crianças de risco. Segundo Linhares (2003 apud CARDOSO et al., 2010), a prematuridade pensada a partir dos aportes do desenvolvimento é uma "porta de entrada" (p. 106) para fatores de risco, tanto biológicos quanto psicossociais, ampliando a possibilidade de adoecimento ou morte no primeiro ano de vida.

Pedromonico (2003 apud CARDOSO et al., 2010) afirma que a prematuridade também pode trazer riscos para o desenvolvimento cognitivo e comportamental, incluindo baixos índices de inteligência e dificuldades acadêmicas no decorrer do desenvolvimento infantil. Apesar de ainda existirem controvérsias quanto a essa afirmação na literatura, os pesquisadores seguem buscando mais informaçóes. Pontes (2009), em um estudo que descreveu a evolução do peso e do perímetro cefálico do nascimento aos 12 meses em idade corrigida de recém-nascidos pré-termo com muito baixo peso, destaca a necessidade de acompanhamento com ênfase nos primeiros anos de vida, inclusive estendendo a investigação para períodos mais longos. Magalhães et al. (2003) apresentam um estudo que dá suporte às evidências de que "[...] crianças com história de prematuridade têm pior desempenho em testes perceptual-motores [...]” (p. 253) e acrescentam um dado novo ainda pouco discutido na literatura: 
"[...] o desempenho inferior dessas crianças em provas de controle postural [...]” (p. 254).

O Rio Grande do Sul elaborou um conjunto de diretrizes voltadas à redução do óbito infantil, com açôes focadas na qualificação da atenção à criança por ocasiáo do nascimento e do primeiro ano de vida, anunciando a meta de redução do coeficiente de mortalidade infantil.

Entre essas açôes, as resoluçôes n. 324/10 da Comissão de Intergestores Bipartite/RS (CIB/RS), de 27 de setembro de 2010 (RIO GRANDE DO SUL, 2010), e n. 105/11, de 12 de maio de 2011 (RIO GRANDE DO SUL, 2011), habilitam e dão suporte financeiro aos ambulatórios especializados no atendimento ao prematuro, por meio do serviço denominado Programa de Seguimento de Prematuros Egressos das UTINs.

São considerados pacientes desse programa os bebês prematuros egressos de UTINs com peso menor que 1.500 g., com a finalidade de prevenir complicaçôes decorrentes da prematuridade, identificando precocemente os desvios de desenvolvimento ou outras doenças, viabilizando intervençôes e dando suporte à criança e às famílias das crianças egressas das UTINs.

O follow-up dos RNs de alto-risco é mais que um ambulatório de acompanhamento de prematuros, trata-se de um insight holístico na Pediatria, uma visão da criança como um indivíduo em todos os seus aspectos: físico, motor, psicológico, cognitivo, afetivo e social (SOCIEDADE ..., 2012, p. 4).

Para o Ministério da Saúde (BRASIL, 2011a), a razáo maior da existência dos programas de seguimento de prematuros (follow-up) é a preocupação básica de estar atento ao desenvolvimento dos bebês para um diagnóstico precoce e orientaçóes específicas quando detectados sinais de alteraçóes ou interferências em seu desenvolvimento.

Além das ações diretamente relacionadas ao atendimento clínico especializado ao bebê e seus familiares, o programa também tem por objetivo avaliar os resultados das terapias empregadas nas UTINs, fornecendo feedback aos neonatologistas que tratam dessa população e encaminhando dados aos gestores de saúde, para um melhor planejamento nas medidas preventivas, conforme estabelecido na resolução n. 324/10-CIB/RS (RIO GRANDE DO SUL, 2010).

Assim, a partir do projeto de extensão Implantação do Serviço de Terapia Ocupacional no Hospital Universitário de Santa Maria, aprovado pela agência de fomento da Universidade Federal (FIEX), protocolo n. 028925, em 2011, foi possível o ingresso de um docente terapeuta ocupacional e alunos da graduação na equipe que compóe o referido programa. Atualmente, a atuação na área da Terapia Ocupacional é de responsabilidade de um terapeuta ocupacional, aluno do Programa de Residência Multiprofissional Integrada ao Sistema Público de Saúde da UFSM.

O artigo, portanto, tem por objetivo apresentar um relato descritivo da experiência de participação de um terapeuta ocupacional junto à equipe e à população atendida no Programa de Seguimento de Prematuros Egressos de UTINs do Hospital Universitário de Santa Maria. O relato é contextualizado pela descrição da proposta do programa de seguimento implantado no HUSM, apresentando também os protocolos definidos pela equipe para avaliação. Em seguida, apresenta-se o processo de inserção do terapeuta ocupacional no programa e, finalmente, são destacadas algumas consideraçóes sobre a contribuição do terapeuta ocupacional junto à equipe e à populaçáo atendida.

\section{O Programa de Seguimento de Prematuros Egressos de UTINs implantado no Hospital Universitário de Santa Maria}

No HUMS, o ambulatório de follow-up do recém-nascido (RN) de risco existe desde 1991, com o objetivo inicial de acompanhar as crianças egressas da UTIN do HUSM. Mas, nesse ano, o serviço foi cadastrado como Programa de Seguimento de Prematuros Egressos de UTINs, ampliando o atendimento para toda a denominada Quarta Regiáo do Estado do Rio Grande do Sul, que corresponde a 31 municípios. O programa deve seguir um protocolo de seguimento de prematuros menores de $1.500 \mathrm{~g}$ egressos de UTI Neonatal (anexo II da resolução n. 324/10 - CIB/RS), no qual há sugestão de equipe, população a ser acompanhada, número de consultas de seguimento e procedimentos especiais. A equipe do programa de seguimento de prematuros do HUSM é composta por pediatra, coordenadora do projeto, alunos de graduação e pós-graduação de Medicina, terapeuta ocupacional e alunos da graduaçáo (Projeto de Extensão), e alunos da Residência Multiprofissional Integrada em Sistema Público de Saúde, incluindo estudantes, além da Terapia Ocupacional, das áreas Fisioterapia, Fonoaudiologia, Enfermagem, 
Psicologia e Nutrição. As demais especialidades são acionadas por meio de encaminhamentos dos serviços oferecidos pela Universidade.

O encaminhamento para o ambulatório de seguimento é realizado na ocasiáo da alta da UTIN, pela equipe de Neonatologia do Hospital Universitário e de outras UTINs da Rede Hospitalar da Quarta Região. $\mathrm{O}$ bebê prematuro com peso inferior a $1.500 \mathrm{~g}$ já sai da UTIN com data prevista para a primeira consulta, que deve acontecer entre $10 \mathrm{a}$ 15 dias após. Pelo programa estadual, o bebê deve ser acompanhado nesse ambulatório até os dois anos e, depois, ser encaminhado à rede básica para continuidade do acompanhamento com menor periodicidade, porém o programa de seguimento do HUSM faz o acompanhamento até os sete anos. A frequência das consultas varia de acordo com a idade do bebê: no primeiro mês é quinzenal; de um aos seis meses o acompanhamento é mensal. De seis a 12 meses, são bi ou trimestrais, dependendo da evoluçáo e da condiçáo familiar para o deslocamento até o serviço de saúde. Segue com periodicidade de atendimento semestral até os quatro anos, e anual até os sete anos.

É importante salientar que todas as idades descritas anteriormente são consideradas a partir da idade corrigida. A idade corrigida, também designada idade pós-concepçáo, traduz o ajuste da idade cronológica em função do grau de prematuridade. Considerando que o ideal seria nascer com 40 semanas de idade gestacional, deve-se descontar da idade cronológica do prematuro as semanas que faltaram para sua idade gestacional atingir 40 semanas (RUGOLO, 2005). Embora não esteja totalmente esclarecido até quando se deve corrigir a idade do prematuro, a maioria dos autores recomenda utilizar a idade corrigida na avaliação do crescimento e do desenvolvimento até os dois anos de idade, a fim de se obter a expectativa real para cada criança, sem subestimar o prematuro ao confrontá-lo com os padrôes de referência (RUGOLO, 2005).

Os atendimentos acontecem uma vez por semana, em um número médio de 15 pacientes. São divididos em três momentos: no primeiro, os bebês e seus familiares sáo avaliados pelos alunos de Medicina. Em um segundo momento, acontece o round, em que o aluno relata suas principais observaçóes e a equipe define quais outros profissionais acompanharão a avaliação (terapeuta ocupacional, fisioterapeuta, psicólogo, nutricionista, fonoaudiólogo ou enfermeiro). A pediatra de referência faz os encaminhamentos da consulta médica e aguarda a avaliaçáo indicada para ampliar os procedimentos. Volta-se a discutir em equipe, pensando quanto às indicaçóes médicas, orientaçóes aos familiares, além de encaminhamentos para exames e tratamentos especializados em estimulação precoce, quando detectado atraso ou risco de atraso no desenvolvimento. $\mathrm{O}$ terceiro momento é o de devolutiva à família, realizado pelos alunos de Medicina e profissionais de outras áreas que participaram da avaliação. A família sai da consulta com os encaminhamentos e com data marcada para seu retorno.

\subsection{Os instrumentos de avaliação}

O Protocolo de Seguimento de Prematuros Menores de $1.500 \mathrm{~g}$ Egressos de UTI Neonatal (anexo II da resolução n. 324/10 - CIB/RS) indica em seu item Procedimentos Especiais, além da obrigatoriedade das triagens auditivas e visuais e dos exames laboratoriais, a avaliação neurológica e de desenvolvimento através dos testes de Alberta (18 meses) ou Bayley (seis anos). Porém, nos estudos realizados pela equipe do programa de seguimento de prematuros do HUSM e considerando as características da clientela e as experiências de outros seguimentos, destacaram-se três protocolos: Teste de Triagem de Desenvolvimento de Denver II, utilizado em outros programas de seguimento, como o do Hospital Conceição, em Porto Alegre; a Escala Bayley de Desenvolvimento Infantil, pela sua eficácia já comprovada; e os Indicadores Clínicos de Risco para o Desenvolvimento Infantil (IRDIs), instrumento brasileiro validado em 2008 - Pesquisa Multicêntrica de Indicadores Clínicos de Risco para o Desenvolvimento Infantil (SOUZA, 2010) e que está sendo utilizado em pesquisa realizada na UFSM intitulada Funçôes parentais e risco para aquisição da linguagem: Intervençôes fonoaudiológicas (SOUZA, 2010).

Os instrumentos, testes, escalas ou inventários para avaliar o desenvolvimento de bebês, têm sido utilizados em pesquisas aplicadas, clínicas e estabelecimentos educacionais, subsidiando a implementação de programas de estimulação precoce, orientando o planejamento de açóes pontuais com crianças e seus cuidadores (NUNES; SISDELLI; FERNANDES, 1995 apud RODRIGUES, 2012). $\mathrm{Na}$ avaliação do desenvolvimento do bebê, entendido em sua globalidade como neuropsicomotor, deve-se destacar a importância do uso de escalas confiáveis, de comprovada sensibilidade e especificidade e que considerem a diversidade cultural dos indivíduos (SANTOS; RAVANINI, 2006 apud SILVA et al., 2011). Assim, justifica-se o uso da Escala Bayley de Desenvolvimento Infantil e do Teste Denver 
nesse contexto populacional. Já o protocolo IRDIs foi trazido pela Terapia Ocupacional para o programa de seguimento de prematuros pois é brasileiro e tem apontado eficácia na identificação de bebês com sintomas psíquicos com risco para seu desenvolvimento. Esses três protocolos seráo resumidamente apresentados com o objetivo de situar a sua eficácia como instrumentos de avaliação da populaçáo em questáo.

\subsubsection{Protocolo Bayley Scale of Infant Development (Bayley III)}

A Escala Bayley de Desenvolvimento Infantil (Bayley Scale of Infant Development - BSID) foi descrita, inicialmente, em 1953, por Nancy Bayley e colaboradores. Ela é composta por propriedades psicométricas para avaliação do desenvolvimento infantil e especialmente de habilidades motoras (RODRIGUES, 2012; SILVA et al., 2011). Assim, a escala permite ao examinador medir a atenção/nível de alerta da criança (abaixo de seis meses), orientaçáo/ engajamento dirigida à atividade, ao examinador e ao cuidador e avalia a regulação emocional e a qualidade do movimento (CAVALCANTI; GALVÁO, 2007).

A Escala Bayley III, publicada em 2006 (TECKLIN, 2007 apud SILVA et al., 2011), é uma atualização dos dados normativos da BSID-II indicada para avaliar crianças de um a 42 meses (três anos e seis meses) de idade - com ou sem deficiências - no diagnóstico de atrasos do desenvolvimento para, consequentemente, planejar estratégias de intervenção (RODRIGUES, 2012).

Trata-se de uma avaliação padronizada das habilidades mentais, motoras e de linguagem composta por 326 itens (MADASCHI; PAULA, 2011) que avaliam cinco domínios do desenvolvimento: cognitivo; motor grosso e fino; linguístico (comunicação expressiva e receptiva); socioemocional; e comportamental (RODRIGUES, 2012).

Segundo Silva et al. (2011):

- Escala Cognitiva (91 itens): Determina como a criança pensa, reage e aprende sobre o mundo ao seu redor;

- Escala de Linguagem (subdividida em dois subtipos): Comunicação Receptiva (49 itens) -determina como a criança reorganiza sons e como ela entende, fala e direciona palavras - e Comunicação Expressiva (48 itens) - determina como a criança se comunica usando sons, gestos e palavras;
- Escala Motora (subdividida em Escala Motora Grossa e Fina): Escala Motora Grossa (72 itens) - determina como a criança movimenta seu corpo em relação à gravidade - e Escala Motora Fina (66 itens) - determina como a criança usa suas máos e dedos para fazer algo.

Os três primeiros domínios são observados com a criança em situação de teste e os dois últimos,por meio de questionários preenchidos pelos pais ou cuidadores (BAYLEY, 2006 apud SILVA et al., 2011).

A Escala Bayley III, segundo Madaschi e Paula (2011), está entre as melhores escalas existentes na área de avaliação do desenvolvimento infantil, sendo considerada "[...] 'padrão ouro' por diversos autores, principalmente por abarcar uma avaliação bem completa e detalhada do desenvolvimento neuropsicomotor [...]" (MADASCHI; PAULA, 2011, p. 55). Os autores seguem afirmando que a utilizaçáo da escala como instrumento de pesquisa tem recebido grande suporte da comunidade científica, tanto para avaliação da população em geral como para avaliação de grupos de risco (prematuros, por exemplo), assim como para a avaliação de transtornos específicos do desenvolvimento, como o autismo.

Para Lordelo et al. (2007 apud SILVA et al., 2011), a utilização da Escala Bayley III no Brasil é possível, porém, com limitações, pois ainda não existe validação para as características da população e da cultura brasileira, devendo ser aplicada apenas por profissionais especializados e treinados.

\subsubsection{Teste de Triagem de Desenvolvimento de Denver II}

O teste de Triagem de Desenvolvimento de Denver II foi desenvolvido por Frankenburg e Dodds, em 1967, com o objetivo de direcionar o cuidado dos adultos para com as crianças com riscos. Por isso é considerado um teste de "triagem" e não de diagnóstico de anormalidades no desenvolvimento. Seu uso foi difundido em muitos países, sofrendo adaptaçóes, o que incitou uma revisão e repadronização do teste, resultando no Teste Denver II, em 1992 (FRANKENBURG, 1992 apud SILVA et al., 2011). É um instrumento de triagem rápida, funcional para equipes com número elevado de pacientes para avaliação em pouco tempo de consulta, aplicado quando há suspeita de atrasos no desenvolvimento ou exposiçáa a fatores de risco (RODRIGUES, 2012), como os pacientes do seguimento de prematuros. Deve ser aplicado em crianças recém-nascidas até os seis 
anos de idade (FRANKENBURG et al., 1992 apud VARGAS, 2010).

O teste possui 125 itens em quatro domínios do desenvolvimento neuropsicomotor, com base em Halpern et al. (2000):

- Pessoal/social: Aspectos da socialização da criança dentro e fora do ambiente familiar;

- Adaptação motora fina: Coordenação olho/ mão, manipulação de pequenos objetos;

- Linguagem: Produção de som, capacidade de reconhecer, entender e usar a linguagem;

- Motricidade ampla: Controle motor corporal, sentar, caminhar, pular.

Os dados são colhidos pela observação direta da criança e, para alguns deles, solicita-se que o cuidador informe se a criança realiza ou não determinada tarefa. Essas respostas são classificadas em: passa (se a criança conseguir realizar a tarefa ou o cuidador relatar que ela faz); falha (se a criança não conseguir realizar a tarefa ou se o cuidador relatar que ela não é capaz de fazê-la); recusa (se a criança recusa-se a cumprir a tarefa); e sem oportunidade (se a criança não teve oportunidade de realizar a tarefa devido a restriçôes dos cuidadores ou por outras razôes) (HALPERN et al., 2000).

Esses dados são apresentados em forma de gráfico, considerando cada marco do desenvolvimento infantil, no qual os resultados sáo registrados e neles é possível observar-se rapidamente o nível de desenvolvimento da criança.

Apesar de o teste não apresentar restriçōes quanto à situação de risco ou não da criança, alguns autores apontam a importância de considerar os resultados levando-se em conta a correçáo de idade pela prematuridade.

\subsubsection{Protocolo Indicadores Clínicos de Risco para o Desenvolvimento Infantil}

Os Indicadores Clínicos de Risco para o Desenvolvimento (IRDIs) foram elaborados a partir de uma pesquisa recentemente implementada no Brasil com financiamento do Ministério da Saúde intitulada Pesquisa Multicêntrica de Indicadores Clínicos de Risco para o Desenvolvimento Infantil (KUPFER, 2008). Nessa pesquisa foi desenvolvido um instrumento (os IRDIs) para identificar indicadores clínicos de risco ao desenvolvimento nos primeiros 18 meses de vida da criança. Os indicadores clínicos da pesquisa foram definidos em quatro eixos fundamentais, elaborados a partir de referenciais psicanalíticos: o estabelecimento de demanda da criança; a suposição de um sujeito; a alternância entre presença-ausência por parte da mãe; e presença de função paterna (alteridade) (KUPFER; BERNARDINO, 2009).

Oliveira, Flores e Souza (2012) apontam que devem ser observados, pela via do bebê, para avaliaçáo do primeiro eixo, estabelecimento de demanda, suas primeiras reaçóes involuntárias e reflexos no percurso dos três primeiros meses, como choro, postura motora, sucção e, pela via da mãe, a forma como a mãe interpreta esses movimentos. A mãe é conduzida, pelo seu desejo de maternagem, a "[...] reconhecer em cada gesto insignificante do filho um signo de demanda endereçada a ela [...]" (OLIVEIRA, FLORES; SOUZA, 2012, p. 338).

O segundo eixo, suposiçáo de um sujeito, refere-se à ideia psicanalítica de que a mãe, na leitura dos movimentos que parecem ser só atitudes reflexas, atribui ao filho um saber, ou seja: coloca o bebê em uma posição de quem tem algo a dizer. Quando essa antecipação, ou essa fala ao bebê, vem acompanhada de uma "[...] manifestação jubilatória da mãe, sob a forma de palavras carregadas de uma musicalidade prazerosa chama de mamanhês [...]" (OLIVEIRA; FLORES; SOUZA, 2012, p. 338), isso fará com que o bebê tente corresponder ou reproduzir a cena na busca de prazer.

O terceiro eixo, alternar presença-ausência, aponta um tempo um pouco além dos três meses, no qual a mãe já consegue colocar-se em uma posição de quem não sabe tudo sobre o filho, ela supóe que o que ela diz não seja suficiente para acalmá-lo, por exemplo. A mãe provoca no bebê o reconhecimento de que ela não está totalmente à disposição como estava antes, ela está e não está fisicamente e ela entende e não entende imaginariamente e no futuro próximo, simbolicamente o seu bebê.

A ausência da mãe marcará para o bebê um espaço vazio, real e imaginário, onde serão introduzidas outras pessoas, outros objetos, a própria linguagem e o simbólico (WINNICOTT, 1975).

Dessa negativa materna institui-se o quarto eixo dos indicadores clínicos de risco para o desenvolvimento infantil: o eixo função paterna, entendido como a lei. Essa lei que vem na forma de regras, normas, que introduz o não. Segundo Dor (1992), a função paterna é entendida como a que produz a separaçấo simbólica entre a mãe e seu bebê. Ele deixa de ser o objeto de pura satisfação da mãe e vice-versa. Para que isso aconteça é preciso que a mãe situe a lei como "[...] uma referência a um terceiro em 
seu laço com a criança [...]" (OLIVEIRA; FLORES; SOUZA, 2012, p. 338), o pai, por exemplo.

Esse circuito construído na relação que se estabelece entre mãe e bebê, somado aos cuidados necessários para a sobrevivência e ao próprio potencial de produção do bebê compóem o entrelaçamento necessário para seu desenvolvimento. A ausência de um dos fatores desse circuito apontará problemas na estruturação subjetiva do bebê e um possível transtorno em seu desenvolvimento.

Entre 2004 e 2008, o grupo de pesquisa elencou 18 IRDIs finais para avaliar bebês e diagnosticar a existência ou não de riscos para o desenvolvimento e riscos psíquicos (OLIVEIRA; FLORES; SOUZA, 2012), considerando os quatro eixos, conforme apresentados no Tabela 1.

Segundo Kupfer e Bernardino (2009), o pressuposto é que esses indicadores clínicos podem ser empregados pelos pediatras e agentes de saúde durante a consulta nas unidades básicas e/ou centros de saúde nos primeiros 18 meses de vida do bebê, podendo ser úteis para detectar precocemente transtornos do desenvolvimento infantil, indicando necessidade de encaminhamento para atendimento clínico especializado.

\section{Relato de experiência da} participação do terapeuta ocupacional na equipe do Programa de Seguimento de Prematuros Egressos de UTINs

No primeiro ano de construção da parceria estadual com o Programa Seguimento de Prematuros Egressos de UTINs como um programa regional e do ingresso do serviço de Terapia Ocupacional nele, efetuaram-se, aproximadamente, 800 consultas e reconsultas médicas, numa média de 400 pacientes. Desses, 80 foram avaliados pelo terapeuta ocupacional.

Apesar da escolha dos instrumentos de avaliação, eles não foram utilizados no primeiro ano. Os três protocolos exigem formação e a equipe está pleiteando recursos humanos e financeiros para tal. Porém as avaliações seguiram, considerando os conhecimentos específicos de cada profissão. O terapeuta ocupacional identificou, entre os 80 pacientes avaliados, três crianças com sintomas psíquicos e encaminhou uma criança com questóes visuais para avaliação, a qual, posteriormente, foi

Tabela 1. IRDIs finais.

\begin{tabular}{|c|c|c|c|}
\hline \multicolumn{4}{|c|}{ IRDIs FINAIS } \\
\hline $\begin{array}{c}\text { De } 0 \text { a } 4 \text { meses } \\
\text { Fase I }\end{array}$ & $\begin{array}{c}\text { De } 4 \text { a } 8 \text { meses } \\
\text { Fase II }\end{array}$ & $\begin{array}{c}\text { De } 8 \text { a } 12 \text { meses } \\
\text { Fase III }\end{array}$ & $\begin{array}{c}\text { De } 12 \text { a } 18 \text { meses } \\
\text { Fase IV }\end{array}$ \\
\hline $\begin{array}{l}1 \text { Quando a criança chora } \\
\text { ou grita, a mãe sabe o que } \\
\text { ela quer. }\end{array}$ & $\begin{array}{l}6 \text { A criança utiliza } \\
\text { sinais diferentes para } \\
\text { expressar suas diferentes } \\
\text { necessidades. }\end{array}$ & $\begin{array}{l}9 \text { A mãe percebe que } \\
\text { alguns pedidos da criança } \\
\text { podem ser uma forma de } \\
\text { chamar a sua atenção. }\end{array}$ & $\begin{array}{l}15 \text { A mãe alterna } \\
\text { momentos de dedicação } \\
\text { à criança com outros } \\
\text { interesses. }\end{array}$ \\
\hline $\begin{array}{l}2 \text { A mãe fala com a } \\
\text { criança num estilo } \\
\text { particularmente dirigido a } \\
\text { ela (mamanhês). }\end{array}$ & $\begin{array}{l}7 \text { A criança reage (sorri, } \\
\text { vocaliza) quando a mãe } \\
\text { ou outra pessoa está se } \\
\text { dirigindo a ela. }\end{array}$ & $\begin{array}{l}10 \text { Durante os cuidados } \\
\text { corporais, a criança } \\
\text { busca ativamente jogos } \\
\text { e brincadeiras amorosas } \\
\text { com a mãe. }\end{array}$ & $\begin{array}{l}16 \text { A criança suporta bem } \\
\text { as breves ausências da } \\
\text { mãe e reage às ausências } \\
\text { prolongadas. }\end{array}$ \\
\hline $\begin{array}{l}3 \text { A criança reage ao } \\
\text { mamanhês. }\end{array}$ & $\begin{array}{l}8 \text { A criança procura } \\
\text { ativamente o olhar da } \\
\text { mãe. }\end{array}$ & $\begin{array}{l}11 \text { Mãe e criança } \\
\text { compartilham uma } \\
\text { linguagem particular. }\end{array}$ & $\begin{array}{l}17 \text { A mãe já não se sente } \\
\text { mais obrigada a satisfazer } \\
\text { tudo que a criança pede. }\end{array}$ \\
\hline $\begin{array}{l}4 \text { A mãe propõe algo à } \\
\text { criança e aguarda a sua } \\
\text { reação. }\end{array}$ & & $\begin{array}{l}12 \text { A criança estranha } \\
\text { pessoas desconhecidas } \\
\text { para ela. }\end{array}$ & $\begin{array}{l}18 \text { Os pais colocam } \\
\text { pequenas regras de } \\
\text { comportamento para a } \\
\text { criança. }\end{array}$ \\
\hline \multirow[t]{2}{*}{$\begin{array}{l}5 \text { Há trocas de olhares } \\
\text { entre a criança e a mãe. }\end{array}$} & & $\begin{array}{l}13 \text { A criança faz } \\
\text { gracinhas. }\end{array}$ & \\
\hline & & $\begin{array}{l}14 \text { A criança aceita } \\
\text { alimentação semissólida, } \\
\text { sólida e variada. }\end{array}$ & \\
\hline
\end{tabular}

Fonte: Kupfer (2008 apud OLIVEIRA; FLORES; SOUZA, 2012, p. 339). 
diagnosticada como cega. As outras três crianças citadas foram encaminhadas para atendimento especializado em estimulação precoce. Outras duas pacientes foram diagnosticadas como em risco social e encaminhadas para acompanhamento do Conselho Tutelar. Para os pacientes restantes dos 80 iniciais, um maior investimento foi feito na sensibilização e nas orientaçóes aos pais quanto à necessidade de oferecer ao bebê uma rotina que considerasse a sua idade corrigida.

Ao final desse primeiro ano, o papel do terapeuta ocupacional como componente da equipe foi consolidado, confirmando a reflexão de Galheigo (1999, p. 52) sobre a "[...] facilidade com que os terapeutas ocupacionais se inscrevem em ações interdisciplinares, assim como, possivelmente, em projetos transdisciplinares [...]". A autora segue propondo que isso se deve à possibilidade de o terapeuta ocupacional exercer diversos olhares e fazer uso de várias línguas ante a problemática determinada.

Nessa perspectiva, a entrada do terapeuta ocupacional no serviço oportunizou a construção de um olhar mais amplo sobre as questóes do desenvolvimento infantil e também sobre a formação profissional das multidisciplinas que compóem o núcleo. O programa de seguimento vinha de uma trajetória de diagnósticos de patologias, de registros de informaçóes para dados de protocolos, como peso, tamanho, etc., e com encaminhamentos para exames padronizados pelo protocolo do seguimento, ou indicados pela necessidade do caso, na perspectiva de Francisco (2001) quando enumera algumas linhas que entendem saúde como ausência de doença. A equipe não tinha tempo nem recursos humanos para observar outras questôes que não as de futuras patologias.

Com o ingresso do terapeuta ocupacional e com ele focando seu olhar nos relatos sobre o cotidiano familiar, considerando a prematuridade do bebê e tudo o que isso envolve, esse cotidiano rapidamente passou a ser mais uma peça analisada para o diagnóstico ou encaminhamento da criança, pois trazia, em muitos casos, uma nova interpretação sobre as informaçóes e sobre o lugar familiar dos cuidados do bebê.

Para Galheigo (2003, p. 107), na "[...] medida em que os estudos sobre o cotidiano incorporam a subjetividade, a cultura, a história e o poder social como elementos que influem na compreensão do fenômeno [...]", eles definitivamente rompem com qualquer leitura de caráter mais positivista.
Quando a família de um bebê prematuro é convocada a falar sobre o seu dia a dia, sobre seu cotidiano, muitas vezes, é tomada por uma surpresa e se cala. O que seria importante falar sobre o bebê e a família para os "doutores" que já não tenha sido tratado? São necessárias estratégias para ampliar o diálogo. O terapeuta ocupacional, a partir de uma perspectiva crítica sobre o lugar do sujeito no mundo, fundamenta-se na "[...] retomada histórica e contextualizada do sujeito e [de] sua inserção participante no coletivo [...]" (GALHEIGO, 2003, p. 108). Coletivo entendido aqui como todas as condiçóes internas e externas dos pais para a criação de seu filho prematuro. Perguntas sobre como conversam mãe e bebê, se o bebê olha para ela e para outros familiares, se ele pede a presença ou alimento e como faz isso, se sente a ausência de alguém, se brinca e como brinca: com o corpo da mãe, com seu corpo, com objetos, são algumas questóes trazidas para a avaliação que nos ajudam a compreender como o bebê está inserido no cotidiano familiar. Entende-se que as atividades cotidianas de mãe e pai são diferentes das atividades de um bebê e, por isso mesmo, deve-se estar atento, pois é compromisso dos pais construírem um dia a dia em que o filho tenha a garantia de estar sendo bem cuidado, mas também importa a ideia de que ele possui seu espaço próprio, seu papel na tríade familiar.

As primeiras experiências envolvendo segurança e confiança se dão no lar, que permite a exploração, a experimentaçáo de diferentes relacionamentos e a ocupação de espaços que a criança preenche com seus próprios fragmentos, tornando-os seus espaços e reconhecendo-os como tal (TAKATORI et al., 2004, p. 257).

A questão da idade corrigida passou a ser tema constante nas entrevistas com as famílias. Ajudar uma mãe e um pai a compreenderem a real idade de seu bebê através do cálculo da idade corrigida pode situá-los quanto aos cuidados oferecidos, quanto aos recursos que o bebê tem para reagir/responder aos cuidados e quanto às comparaçôes, inevitáveis, com outras crianças nascidas a termo. Quando um terapeuta ocupacional se coloca à disposiçâo desses pais para escutá-los e compreendê-los, a partir das histórias que compóem seu cotidiano, eles produzem alternativas de intervenções reais que vão contribuir para "[...] prover um ambiente que promova a saúde de cada criança por meio da contínua oferta de experiências saudáveis, que transformem cada instante seu em um acontecimento [...]" (TAKATORI et al., 2004, p. 258). 
Com isso, por exemplo, a máe que, à primeira vista, foi considerada negligente pelo baixo peso do filho, quando escutada pelo terapeuta ocupacional pode mudar de lugar, sendo, nesse caso, encaminhada à Assistência Social em busca de recursos financeiros para alimentação adequada. O bebê que, mesmo em idade corrigida, já deveria caminhar, diagnosticado com atraso no desenvolvimento, passa a fazê-lo dois meses após a consulta, pela retirada do andador indicada pelo terapeuta ocupacional. A mãe, triste pela ausência do pai durante a semana, pois o mesmo trabalha em outra cidade, e o pai, com sua angústia diante do medo do esquecimento da filha, reposicionam-se nas suas relaçôes familiares. Com a ajuda do terapeuta ocupacional, descobrem formas de manterem-se presente mesmo na ausência, com fotos do pai, dele com a filha e da família inteira e com a realização de atividades desenvolvidas para serem oferecidas a ele por telefone e pessoalmente, no seu retorno.

Como foi apresentado, o programa de seguimento também identificou e encaminhou pacientes com patologias ou transtornos com sérios riscos para o desenvolvimento. O terapeuta ocupacional foi importante em alguns desses casos, como, por exemplo, para o bebê encaminhado a novo exame oftalmológico, e que, após a cegueira diagnosticada, foi encaminhado para tratamento em estimulação precoce. As avaliaçóes em Terapia Ocupacional no programa de seguimento de prematuros, mesmo náo utilizando os protocolos nesse primeiro ano de trabalho, foram embasadas considerando-se a globalidade do desenvolvimento do bebê em seus aspectos físico, cognitivo e psíquico. Para o bebê acima referido, foi a escuta do terapeuta ocupacional do relato da avó (que o trazia para as avaliaçóes) sobre como náo fixava o olhar nos familiares, não seguia os objetos, se angustiava com mudanças bruscas de sons e de ambiente e como dormia muito que direcionou, além da avaliação no momento da consulta tomada como preocupante, a equipe ao encaminhamento para o serviço de oftalmologia e para o tratamento de estimulação precoce.

\section{Considerações finais}

A importância do serviço no Programa de Seguimento de Prematuros Egressos de UTINs em nível nacional e regional já está consolidada não só pela legislação, que garante esse acompanhamento, mas principalmente pela quantidade de crianças encaminhadas para outros tipos de tratamento. Esse programa do HUSM tem avançado na qualificação dos serviços oferecidos, ampliando seu campo de visão sobre o paciente e seus familiares, principalmente pela abertura à compreensão desses sujeitos sob outras ópticas que náo só a do binômio saúde/doença.

O terapeuta ocupacional tem contribuído junto à equipe de profissionais, diferenciando-se quanto ao foco da investigaçáo, pois mesmo considerando a importância de um desenvolvimento adequado à idade, corrigida ou não, amplia a escuta à família sobre o dia a dia na criação do filho e, com isso, direciona o olhar também para os fatores externos à prematuridade orgânica do bebê. $\mathrm{O}$ programa de seguimento tem também a função de ajudar essas famílias que receberam seus bebês muito mais cedo do que esperavam e em condiçóes de saúde nunca desejadas a reconhecerem no bebê táo pequeno seus traços familiares, a descobrirem um potencial de maternagem que talvez ainda não conhecessem e a contarem com uma equipe atenta a essas questóes e também às orgânicas. A cada paciente atendido pelo terapeuta ocupacional aprende-se que nada do que é estudado na graduação e na pós-graduação é suficientemente importante se não estiver a serviço da história, da cultura e das necessidades do sujeito a quem dispomos nosso saber.

\section{Referências}

BRASIL. Ministério da Saúde. Portaria no 693/GM, de 5 de julho de 2000. Atenção humanizada ao recémnascido de baixo peso: método canguru. Diário Oficial da República Federativa do Brasil, Brasília, 5 jul. 2000. Seção 1. Disponível em: <http://portal.saude.gov.br/ portal/arquivos/pdf/manual_canguru_site.pdf $>$. Acesso em: 14 jan. 2012.

BRASIL. Ministério da Saúde. Portaria n 2799, de 18 de novembro de 2008. Rede Amamenta Brasil. Diário Oficial da República Federativa do Brasil, Brasília, 19 nov. 2008. Seção 1. Disponível em: <http://dtr2001.saude.gov. br/sas/PORTARIAS/Port2008/GM/GM-2799.htm>. Acesso em: 14 jan. 2012.

BRASIL. Ministério da Saúde. Secretaria de Atenção à Saúde. Atenção humanizada ao recém-nascido de baixo peso: método mãe-canguru: manual do curso. Brasília: Ministério da Saúde, 2011a. (Série A. Normas e Manuais Técnicos). Disponível em: <http://www.redeblh.fiocruz. br/media/manualcanguru.pdf>. Acesso em: 24 jan. 2012.

BRASIL. Ministério da Saúde. Secretaria da Saúde. Portaria no 650, de 5 de outubro de 2011. Rede Cegonha. Diário Oficial da República Federativa do Brasil, Brasília, 6 out. 2011b. Seção 1. Disponível em: <http://bvsms.saude. gov.br/bvs/saudelegis/ sas/2011/prt0650_05_10_2011. html>. Acesso em: 15 jan. 2012.

CARDOSO, A. S. et al. Estudo exploratório de dor em recém-nascidos pré-termos em uma unidade de tratamento intensivo neonatal. Cadernos de Terapia Ocupacional da UFSCar, São Carlos, v. 18, n. 2, p. 105-14, ago. 2010. Disponível em: <http://www. cadernosdeterapiaocupacional. ufscar.br/index.php/ 
cadernos/article/viewFile/349/278>. Acesso em: 18 mar. 2012.

CAVALCANTI, A. A. S.; GALVÃO, C R. C. Terapia Ocupacional: fundamentaçấo e prática. Rio de Janeiro: Guanabara Koogan, 2007.

DINIZ, S. G. Gênero, saúde materna e o paradoxo perinatal. Revista Brasileira Crescimento e Desenvolvimento Humano, São Paulo, v. 19, n. 2, p. 313-26, ago. 2009.

DOR, J. Introdução à leitura de Lacan: o inconsciente estruturado como linguagem. Porto Alegre: Artes Médicas, 1992. PMCid:PMC192428

FRANCISCO, B. R. Terapia Ocupacional. 4. ed. Campinas: Papirus, 2001. PMCid:PMC30108

GALHEIGO, S. M. A Transdisciplinaridade enquanto princípio e realidade das açôes de saúde. Revista de Terapia Ocupacional da Universidade da USP, São Paulo, v. 10, n. 2-3, p. 49-54, maio/dez. 1999.

GALHEIGO, S. M. O cotidiano na terapia ocupacional: cultura, subjetividade e contexto histórico-social. Revista de Terapia Ocupacional da USP, São Paulo, v. 14, n. 3, p. 104-153, 2003.

HALPERN, R. et al. Fatores de risco para suspeita de atraso no desenvolvimento neuropsicomotor aos 12 meses de vida. Jornal de Pediatria, Rio de Janeiro, v. 76, n. 6, p. 421-428, 2000.

KUPFER, M. C. M. Relatório científico final: Leitura da constituição e da psicopatologia do laço social por meio de indicadores clínicos: uma abordagem multidisciplinar atravessada pela psicanálise (PT Fapesp) - no 2003/09687. Sáo Paulo: Instituto de Psicologia da Universidade de Sáo Paulo, 2008.

KUPFER, M. C. M.; BERNARDINO, L. M. F. As relaçóes entre construção da imagem corporal, função paterna e hiperatividade: reflexóes a partir da Pesquisa IRDI. Revista Latinoamericana de Psicopatologia Fundamental, São Paulo, n. 1, p. 45-58, mar. 2009.

MADASCHI, V.; PAULA, C. S. Medidas de avaliaçấo do desenvolvimento infantil: uma revisão da literatura nos últimos cinco anos. Cadernos de Pós-graduação em Distúrbios do Desenvolvimento, São Paulo, v. 11, n. 1, p. 52-56, 2011. Disponível em: <http://www. mackenzie.br/fileadmin/Graduacao/CCBS/Pos-Graduacao/ Docs/Cadernos/Volume_11/Madaschi_e _Paula_ v_ 11_n_1_2011.pdf>. Acesso em: 23 abr. 2012.

MAGALHÁES, L. C. et al. Estudos Comparativos sobre o Desempenho Perceptual e Motor na idade escolar em crianças nascidas pré-termo e a termo. Arquivos de Neuropsiquiatria, São Paulo, v. 61, n. 2A, p. 250-255, junho 2003. http://dx.doi.org/10.1590/S0004-282X2003000200016

MARTINEZ, C. M. S. et al. Suporte informacional como elemento para orientaçáo de pais de pré-termo: um guia para o serviço de acompanhamento do desenvolvimento no primeiro ano de vida. Revista Brasileira de Fisioterapia, São Carlos, v. 11, n. 1, p. 73-81, jan./fev., 2007. http:// dx.doi.org/10.1590/S1413-35552007000100012

OLIVEIRA, L. D.; FLORES, M. R.; SOUZA, A. P. R. Fatores de risco psíquico ao desenvolvimento infantil: implicaçôes para a fonoaudiologia. Revista CEFAC, São
Paulo, v. 14, n. 2, p. 333-342, mar./abr. 2012. http:// dx.doi.org/10.1590/S1516-18462011005000054

PONTES, T. B. Crescimento e Desenvolvimento de Recém-nascidos pré-termo com muito baixo peso no primeiro ano de vida. Cadernos de Terapia Ocupacional da UFSCar, São Carlos, v. 17, n. 2, p. 85-169, jul./dez. 2009.

RIO GRANDE DO SUL. Secretaria da Saúde. Resoluçáo no 324/10, de 27 de setembro de 2010. Comissão Intergestores Bipartite/RS. Diário Oficial do Estado do Rio Grande do Sul, Pelotas, 28 set. 2010. Seção 1. Disponível em: <http://www.saude. rs.gov. br/ upload/1340219892_cibr324_10.pdf>. Acesso em: 16 jan. 2012.

RIO GRANDE DO SUL. Resolução no 105/11, de 12 de maio de 2011. Comissão Intergestores Bipartite/RS. Diário Oficial do Estado do Rio Grande do Sul, Pelotas, 13 maio 2011. Disponível em: <http://www.saude.rs.gov. br/upload/ 13.40219892_cibr324_10.Pdf>. Acesso em: 14 jan. 2012.

RODRIGUES, O. M. P. R. Escalas de desenvolvimento infantil e o uso com bebês. Educar em Revista, Curitiba, v. 43, p. 81-100, jan./mar. 2012. http://dx.doi.org/10.1590/ S0104-40602012000100007

RUGOLO, L. M. S. S. Crescimento e desenvolvimento a longo prazo do prematuro extremo. Jornal de Pediatria, Rio de Janeiro, v. 81, n. 1, p. S101-S110, 2005. Suplemento 1. http://dx.doi.org/10.1590/S0021-75572005000200013

SILVA, N. D. S. H. et al. Instrumentos de avaliação do desenvolvimento infantil de recém-nascidos prematuros. Revista Brasileira de Crescimento e Desenvolvimento Humano, São Paulo, v. 21, n. 1, p. 85-98, 2011. Disponível em: <http://www.journals.usp.br/jhgd/article/ viewFile/19998/22084>. Acesso em: 25 abr. 2012.

SOCIEDADE BRASILEIRA DE PEDIATRIA DO ESTADO DO RIO DE JANEIRO - SOPERJ. Novo Manual de Follow-up do Recém-Nascido de Alto Risco/2012. Rio de Janeiro: SOPERJ, 2012. Disponível em: <http:// www.sbp.com.br/show_item2.cfm?id_categoria=24\&id_ detalhe=317\&tipo_detalhs $>$. Acesso em: 26 jan. 2013.

SOUZA, A. P. R. Funçōes parentais e risco para aquisiçāo da linguagem: intervençôes fonoaudiológicas. CAEE n. 0284.0.243.000-09. Santa Maria: Universidade Federal de Santa Maria, 2010.

TAKATORI, M. et al. O Hospital e a Assistência em Terapia Ocupacional com a Populaçáo Infantil. In: DE CARLO, M. M. R. P.; LUZO, M. C. M. (Orgs.). Terapia Ocupacional: reabilitaçáo física e contextos hospitalares. São Paulo: Roca, 2004. p. 256-75.

VARGAS, N. C. M. Seguimento até a idade escolar de recém-nascidos prematuros e a termo com intercorrências neonatais. 2010. 151 f. Dissertação (Mestrado em Ciências da Saúde)-Universidade Federal do Paraná, Londrina, 2010. Disponível em: <http://hdl.handle.net/1884/26424>. Acesso em: 25 abr. 2012.

WINNICOTT, D. W. O brincar \& a realidade. Rio de Janeiro: Imago, 1975. 


\section{Contribuição dos Autores}

Todas as autoras contribuíram com a redação do manuscrito e aprovaram sua versão final.

\section{Notas}

${ }^{1}$ Este artigo relata a experiência da participação do terapeuta ocupacional junto à equipe e à população atendida no Programa de Seguimento de Prematuros Egressos da UTINs vinculado ao Hospital Universitário da Universidade Federal de Santa Maria, RS. Todos os procedimentos éticos necessários foram realizados.

${ }^{2}$ Disponível em: http://bvsms.saude.gov.br/bvs/pnds/.

${ }^{3}$ Portaria n. 650, de 5 de outubro de 2011 (BRASIL, 2011b).

${ }^{4}$ Portaria n. 2.799, de 18 de novembro de 2008 (BRASIL, 2008).

${ }^{5}$ Portaria n. 693/GM, de 5 de julho de 2000 (BRASIL, 2000). 